\title{
PENGARUH KUALITAS PRODUK, CITRA MEREK, DAN HARGA TERHADAP MINAT BELI PRODUK SEPEDA MOTOR HONDA (STUDI PADA MAHASISWA FAKULTAS EKONOMI MANAJEMEN UNIVERSITAS KADIRI)
}

\author{
Muhaimin Daud; Andi Artonơ; Eni Prastiti \\ Fakultas Ekonomi - Universitas Kadiri \\ "E-mail : andi_artono@unik-kediri.ac.id
}

\begin{abstract}
His research aims to determine the effect of product quality and brand image, with prices on the interest of buyers of Honda brand motorcycles. The research he conducted on students at the University Attended the Faculty of Economics at the Management Study Program. The population in this research is that students at the University Attend the Faculty of Economics at the Management Study Program, which at this time used Honda motorbikes and the products known are Honda motorcycles. The sample is determined by purposive sampling method with the number of respondents as many as 100 people. The collection of data is done using a method of providing questionnaires / questions to respondents who are students of the Faculty of Economics at the Management Study Program at Kadiri University. The hypothesis is tested using Ttest and Ftest. The result of the test is able to explain the variables of buying interest totaling $55 \%$ and the remaining $44.6 \%$ explained by other variables not included in the study.
\end{abstract}

Keywords: Product Quality, Brand Image, Price, Buying Interest.

\begin{abstract}
ABSTRAK
Penelitiannya ini bertujuan mengetahui pengaruh kualitas produk dan citra merek, dengan harga terhadap peminatan pembeli sepeda motor merek honda. Penelitian yang ini dilakukannya ke pada mahasiswa/wi di Universitas Kadiri Fakultas Ekonomi di Prodi Manajemen. Populasinya dalam penelitiannya ini yaitu mahasiswa di Universitas Kadiri Fakultas Ekonomi di Prodi Manajemen yang saat yang ini digunakan sepeda motor honda dan yang diketahui produknya yaitu sepeda motor honda. Sampelnya ditentukan oleh metode purposive sampling dengan jumlahnya responden sebanyak 100 orang. Pengumpulannya data dilakukan menggunakan cara memberikan daftar kuesioner/pertanyaan kepada responden adalah mahasiswa/wi Fakultas Ekonomi di Prodi Manajemen di Universitas Kadiri. Hipotesisnya di uji menggunakan Ttest dan Ftest. Hasilnya pengujian mampu bisa menjelaskan variabelnya peminat beli sebesar total $55 \%$ dan sisanya 44,6\% dijelaskan oleh dengan variabel lain tidak dimasukan dalam penelitian.
\end{abstract}

Kata Kunci : Kualitas Produk, Citra Merek, Harga, Minat Beli. 


\section{PENDAHULUAN}

\section{Latar Belakang}

Berkembang perekonomian di Indonesia saat ini sangatlah naik, dikarenakan perkembngan teknologinya yang sangat pesat. Dari kebutuhan primer sampai kebutuhannya sekunder yang ada pada akhirnya di jadikan negara indonesia menjadikan sebuah pangsa pasar terbesar/global yang diminati oleh distributor.

Salah satu contoh yang konkrit adalah kebutuhan sepeda motor yang sangat diminati oleh masyarakat. Dari kalangan atas, umum menengah, dan umum kebawah juga berlomba-lomba berpacu untuk dapat memiliki kebutuhan sekunder dan yang satu ini.

Di negara Indonesia sepeda motor sangatlah digunakan, bukanlah hanya untuk ajang gengsi tetapi juga dapat dilakukan aktifitasnya yang lebih efektif dan efisien. Dikarenakan semakin banyaknya kemacetan terjadi di negara Indonesia sehingga sepeda motor jadi pilihan utama mengatasinya kemacetan.

Dari segi kegiatan marketing sebuah produk, produsennya akan melihat juga peluang apa yang ada di konsumen. Produsennya juga akan memperhatikan bagaimana cara menarik minat pembeli konsumen yang akan produk mereka. produsen akan lebih perhatian produknya dari segi yang diminati konsumen. Begitupun dengan yang dilakukan oleh produsennya sepeda motor Honda.

Reputasi mereka dalah sesuatu cara untuk konsumen yang menentukan pilihannya. bagaimana produk itu baik, dan layak dipakai, atau segala macam-macam pertanyaan yang memungkinkan akan pertanyaan. Sehingga produsen akan lebih perhatian untuk segi citra merek agar dapat bersaing dengan produknya yang sesudah berpengalaman didalam pasar.

Harganya menjadikan salah satu faktor penentuan selain Harganya juga menjadi pertimbangan bagi konsumennya untuk membeli ataupun menggunakan suatu produknya atau jasanya. Harganya salah satu variabel didalam pemasarannya, yang dimanapun harga dapat terpengaruhi konsumen didalam pengambilan keputusannya untuk membelikan sesuatu produknya. Harganya produk sepeda motor Honda bisa dibicarakan terlebih murah dari pada harganya produk pesaingnya, sehingga saat ini mendapat memudahkan produsennya untuk menarik minatnya pembelian.

Pembelian merupakan tujuannya dalam memprosesan marketing. Keinginan membeli ini menciptakan suasana motivasi yang selalu terbayangkan dalam 
mengaktulisasikan apa yang ada di dalam perasaannya Citra merek atau biasa disebut brand image, dan harga bisa mempengaruhi seseorang dalam menentukan minat membeli suatu produ (Ruhamak \& Rahayu, 2016). Kualitas layanan juga menjadi perhatian penting dalam pertimbangan calon konsumen (Pangastuti, 2018).

Berdasarkan latar belakang diatas, peneliti tertarik untuk melakukan penelitian yang berjudul "Pengaruh Kualitas Produk, Citra Merek, Dan juga Harga Terhadap Peminat Pembelian Produknya Sepeda Motor Honda (Studi kasus Pada Mahasiswa di Fakultas Ekonomi Manajemen Universitas Kadiri)".

\section{RumusanMasalah}

Berdasarkan diuraian latar belakang yang diatas adalah ada berapa pokok masalah yang menjadikan arahan pembahasan penulisan didalam penelitian, yaitu :

1. Apakah dapat mempengaruhi kualitas produk terhadap minat pembeli Sepeda Motor Merek Honda?

2. Apakah dapat mempengaruhi citra merek terhadap pembeli Sepeda Motor Merek Honda?

3. Apakah dapat mempengaruhi harga terhadap peminatan pembeli Sepeda Motor Merek Honda?

4. Apakah dapat mempengaruhi kualitas produk, citra merek, dan harga terhadap peminatan Pembeli Sepeda Motor Merek Honda?

\section{PembatasanMasalah}

1. Penelitian inipun membatasi pada pengaruh kualitas produk, citra merek, dan harganya terhadap peminatan pembelian produk sepeda motor Honda.

2. Penelitian inipun melakukan di Universitas Kadiri Fakultas Ekonomi

\section{Tujuan Penelitian}

1. Untuk dapat ngetahui pengaruh berkualitas produknya terhadap peminat pembelian Sepeda Motor Honda.

2. Untuk melihat pengaruh citra brand terhadap peminat pembeli Sepeda Motor Honda.

3. Untuk mengetahui pengaruh apakah harga terhadap minat pembeli Sepeda Motor Honda.

4. Untuk mengetahui pengaruh apakah kualitas produk, citra merek, dan harga terhadap peminat pembeli Sepeda Motor Honda. 


\section{Manfaat Penelitian}

Ada juga pemanfaatan dan pengharapkan didalam penelitian ini yaitu dengan hasil penelitian saat ini mengharapkan bisa memberikan penjelasannya secara jelas didalam bentuk dan pembangunan peminatan pembelian melalui kualitas produk, citra merek, dan harga. untuk penelitian selanjutnya dalam membangun minat beli.

\section{TINJAUAN PUSTAKA}

\section{Kualitas produk}

Kualitas (quality) yaitu (kotler, 2009). Kalau marketing diperhatikan kualitasnya, dan juga bahkan memperkuat dengan promosi dan harga yang sewajarnya maka si konsumen tidak pernah berpikir panjang untk melakukannya dipembelian terhadap produknya. Menurut Gavin dan A. Dale Timpe (dalam Alma, 2011) dapat di tawarkan sebagai usaha dalam mendapatkan keuntungan perusahaan yang didapat dari kegiatan pemenuhan kebutuhan konsumennya .Kualitasnya produksi artinya kemampuannya sebuah produknya didalam peragakan fungsinya, hal ini masuk diseluruh durabillitas, reabilitas, tepat, mudah operasian dan reparasinya dan produknya juga atributsi produknya yang lainnya. Kualitasnya produk membentuk oleh berapa indikator diantaranya mudah dalam penggunaannya, daya tahannya, kejelasannya sebagai fungsi, keragamannya dan ukuran produknya,

Menurut Kotler dan Amstrong (2004) kualitasnya produk yaitu kemampuannya sesuatu produknya untuk melakukannya fungsi, kemampuannya itu meliputinya, daya tahannya, kehandalannya, ketelitiannya yang menghasilkan, kemudahan operasi dan perbaikan, dan atributnya yang lain harga juga produknya secara menyeluruh.

Menurut Tjiptono (2008), kualitasnya mencerminkan seluruh dimensi penawarannya produknya yang hasilkan manfaatkan (benefits) berbagi pelanggannya. Kualitasnya sesuatu produk sebaik rupa barangnya atau jasa ditentukan melalui dimensi-dimensinya. Dimensinya berkualitas produknya menurut Tjiptono (2008) adalah :

1. Performance (kinerja)

2. Durability (daya tahan)

3. Corformance to specifications (kesesuian dengan spesifikasi)

4. Features ( fitur), 
5. Reability (reabilitas),

6. Aesthetics (estetika),

7. Perceived quality ( kesan kualitas),

8. Serviceability, yaitu speed dan kemudahan, kompetensi, keramahan

\section{Citra Merek}

Citra merek yaitu nilai konsumennya terhadap brand tersebut didalam sebuah pasarnya (Aaker dan Biel, 1993). Citra terdapat cipta dasarkan pengelaman pribadi ataupun dengar reputasinya dari orang-orang ataupun medianya.

Citra merek yaitu kumpulan asosiasinya ngenai sesuatu brand yang disimpan didalam perasaan ataupun pikiran konsumennya (Schiffman dan Kanuk, 2007). Menurut Schiffman dan Kanuk (2007), mengatakan ada berapa faktor-faktor yang bisa mempengaruhinya bentukan citra mereknya yaitu :

1. Kualitas atau mutu

2. Dipercaya atau diandalkan,

3. Kegunaan atau manfaat produk dimanfaatkan oleh konsumennya.

4. Harga

5. Citra yang dimiliki oleh brand

\section{Harga}

Konsumen yaitu individual dan karakter yang berbeda. Penilaiannya merasakan disetiap konsumennya disuatu produknya ataupun jasa yang mereka dapat tidak sama. Persepsinya seorang konsumen terhadap sesuatu harga didapat mempengaruhinya keputusan didalam pembelian sesuatu produknya sehingga sesuatu perusahaan harus bisa memberi persepsinya yang lebih baik terhadap produknya ataupun jasa yang mereka jual.

Menurut Tjiptono (1999) terdapat dua faktor utama yang perlu dipertimbangkan dalam pemberian harga adalah:

1) Faktor internalnya yaitu perusahaan

a. Tujuannya Pemasaran adalah Perusahaan

b. Strategi dari Bauran Pemasaran

c. Biayanya

2) Faktornya Eksternalnya di Perusahaan

a. Sifatnya dari pasar dan permintaan 
b. Persaingannya

c. Faktor di eksternal lain

Menurut Stanton (2010: 24), ada empat indikator yang mencirikan harga adalah

1. Terjangkaunya harga

2. Sesuai harganya dengan kualitas produknya

3. Daya pesaing harganya

4. Sesuai harganya dengan manfaatnya.

\section{Minat Beli}

Menurut Ferdinand (2002), yaitu indikatornya peminat pembelian meliputi, adalah :

1. Peminatan eksploratifnya

2. Peminatan referensialnya

3. Peminatan Transaksionalnya

4. Peminatan Preferensialnya

\section{Kerangka Berpikir}

\section{Gambar 1. Kerangka Berpikir}

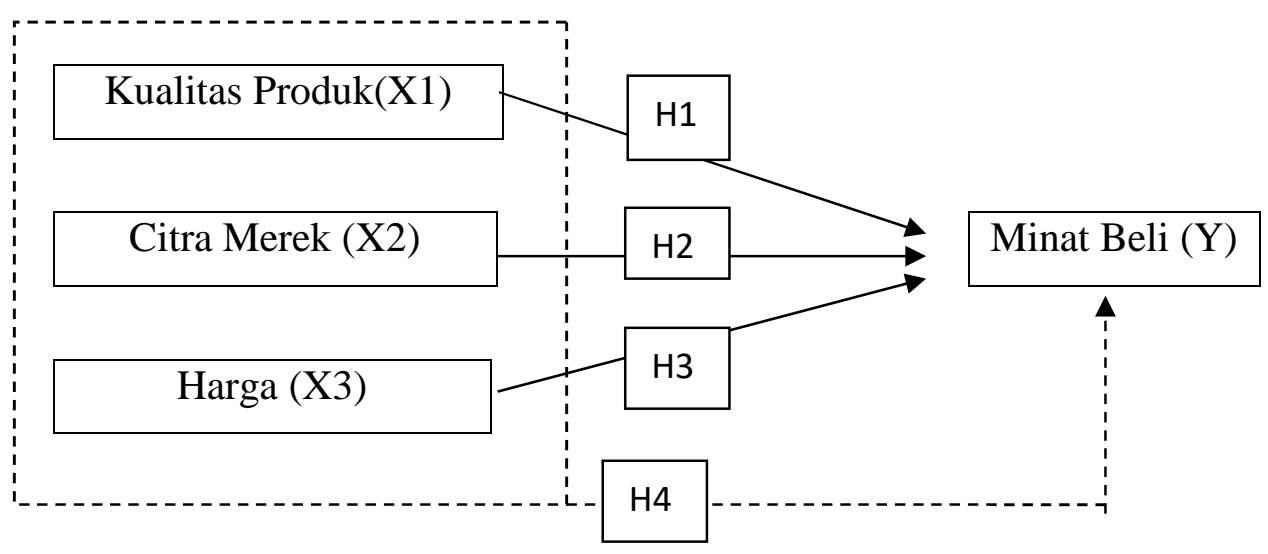

Sumber : Data primer yang diolah (2018)

Keterangan :

$\longrightarrow$ Berpengaruh secara parsial

-..- Berpengaruh secara simultan

\section{METODE PENELITIAN}

\section{Populasi dan Sampel}

\section{Populasi}


Populasi saat penelitian ini yaitu Mahasiswa/wi Fakultas Ekonomi Manajemen di Universitas Kadiri sebanyak 1184 orang.

\section{Sampel}

Penelitiannya menggunakan sampel sebanyak 100 orang.

\section{Metode pengambilan sampel}

Didalam penelitiannya saat ini teknik yang mengunakan didalam teknik pengambilan sampelnya adalah menggunakan metodenya purposive sampling, populasinya dan sampelnya yang diambili mempunyai karakter tertentu. Karakter tersebut antara lain yaitu:

1. Jenis Kelamin

2. Semester

3. Pengguna Sepeda Motor Honda

4. Mahasiswa Fakultas Ekonomi Universitas Kadiri

\section{Metode Pengumpulan Data}

Dalam penelitian ini kuesioner (angket) diberikan kepada responden untuk mengetahui ada atau tidaknya pengaruh kualitas produk, citra merek, dan harga terhadap minat beli pada mahasiswa Fakultas Ekonomi Universitas Kadiri.

\section{Metode Analisis Data}

\section{Uji Instrumen Penelitian}

a. Uji Validitas

Uji validitas dapat menggunakan rumus korelasi berdasarkan Pearson Product Moment adalah sebagai berikut:

$$
\operatorname{rxy}=\frac{\mathrm{n} x y-(\mathrm{x})(\mathrm{y})}{\sqrt{\left(\mathrm{nx^{2 } - ( x ) ^ { 2 } ) - ( n y ^ { 2 } - ( \mathrm { y } ) ^ { 2 }}\right)}}
$$

Dimana:

$$
\begin{aligned}
\mathrm{r} & =\text { Koefisien korelasi } \\
\mathrm{n} \quad & =\text { Banyaknya sampel } \\
\mathrm{xy} & =\text { Jumlah perkalian Variabel } \mathrm{x} \text { dan } \mathrm{y} \\
\mathrm{x} & =\text { Jumlah nilai variabel } \mathrm{x} \\
\mathrm{y} & =\text { Jumlah nilai variabel y } \\
\mathrm{x}^{2} & =\text { Jumlah pangkat dua nilai variabel } \mathrm{x} \\
\mathrm{y}^{2} & =\text { Jumlah pangkat dua nilai variabel } \mathrm{y}
\end{aligned}
$$


b. Uji Reabilitas

Jika koefisien cronbach alpha > 0,6 menunjukan reliabel

Jika koefisien cronbach alpha $<0,6$ menunjukan tidak reliabel.

c. Uji f/ Uji ANOVA (Uji Signifikasi Simultan)

Uji f yaitu uji bias untuk memperlihatkan sejauhmana pengaruh di semua variabel independennya (bebas) bersamaan terhadap variabel dependen (terikat). Langkah-langkahnya pengujiannya ujinya f yaitu sebagai berikut:

1. Derajatnya kepercayaan $5 \%$

2. Derajatnya kebebasan $\mathrm{f}$ tabel $(\alpha, \mathrm{k}, \mathrm{n}-\mathrm{k}-1)$

$\alpha=0,05$

$\mathrm{k}=$ jumlahnya variabelnya bebas

$\mathrm{n}=$ jumlahnya sampelnya

3. Menentukannya kriterianya pengujiannya

Ho ditolak jika f nya hitung $>\mathrm{f}$ tabel.

Ha ditolak jika $f$ nya hitung $<\mathrm{f}$ tabel

4. Menentukan $\mathrm{f}$ nya dengan rumusnya

$$
\mathrm{f}=\frac{\mathrm{R}^{2} / \mathrm{k}}{\left(1-\mathrm{R}^{2}\right) /(\mathrm{n}-\mathrm{k}-1)}
$$

Dimana:

$\mathrm{R}^{2}=$ koefisien determinasi

$\mathrm{n}$ = jumlah sampel

$\mathrm{k}=$ jumlah variabel bebas

Apabila $\mathrm{f}$ hitung $<\mathrm{f}$ tabel maka Ho diterima dan Ha ditolak artinya tidak ada pengaruh secara simultan.

Apabila $\mathrm{f}$ hitung $>\mathrm{f}$ tabel maka Ho ditolak dan Ha diterima artinya ada pengaruh secara simultan.

d. Koefisien Determinasi

Penelitian ini menggunakan banyak variabel bebas sehingga lebih baik jika menggunakan Adjusted R2 agar hasil uji yang dilakukan tidak bias terhadap jurnal variabel bebas yang dimasukan ke dalam model, sehingga hasilnya lebih valid. 


\section{HASIL PENELITIAN DAN PEMBAHASAN}

Deskriptif Penelitian

\section{Karakretistik Responden}

Pengaruh kualitas produk, citra merek, dan harga terhadap minat beli produk sepeda motor Honda'. Dalam penelitian ini identitas responden diidentifikasi berdasarkan faktor-faktor demografi yang meliputi:jenis kelamin dan semester. Dari 100 kuesioner yang disebarkan kepada 100 responden, maka diperoleh gambaran dari responden sebagai berikut:

1. Data dari Responden berdasar jenis kelaminnya yaitu:

Tabel 1. Responden Jenis Kelamin

\begin{tabular}{|cccc|}
\hline No. & Jenis Kelamin & Frekuensi & Presentase ( \% ) \\
\hline 1. & Laki-laki & 42 & 42 \\
2. & Perempuan & 58 & 58 \\
\hline & Total & $\mathbf{1 0 0}$ & $\mathbf{1 0 0}$ \\
\hline
\end{tabular}

Sumber: datanya primer yang telah diolah dengan SPSS Versi 23 (2018)

Dari hasil di atas dapat diketahui total responden perempuannya melebihi besarnya total responden laki-laki, dimana jumlah responden perempuan sebesar $58 \%$, sedangkan responden laki-laki hanya $42 \%$. Data tersebut dapat diindikasikan bahwa sebagian besar responden yang menggunakan sepeda motor Honda di Universitas Kadiri Jurusan Ekonomi Manajemen adalah perempuan.

2. Data Responden Berdasarkan Semester

Tabel 2. Responden Berdasarkan Semester

\begin{tabular}{|cccc|}
\hline No. & Semester & Frekuensi & Presentase ( \% ) \\
\hline 1. & Semester 2 & 19 & 19,0 \\
2. & Semester 4 & 23 & 23,0 \\
3. & Semester 6 & 33 & 33,0 \\
4. & Semester 8 & 25 & 25,0 \\
\hline & Total & $\mathbf{1 0 0}$ & $\mathbf{1 0 0}$ \\
\hline
\end{tabular}

Sumber: datanya primer yang telah diolah dengan SPSS Versi 23 (2018)

Dari diatas menunjukan bahwa dari 100 responden, respendon dari semester 2 sebesar 19 responden atau sebesar 19\%, dari semester 4 sebesar 23 responden atau sebesar 23\%, dari semester 6 sebesar 33 responden atau sebesar 33\%, dan dari semester 8 sebanyak 25 responden atau sebesar 25\%. Dari data yang peroleh maka yang paling banyak menggunakan seped motor Honda adalah semester 6. 


\section{KESIMPULAN DAN SARAN}

\section{Kesimpulan}

1. Berdasarkan hasil dari uji parsial (t-hitung) terpengaruh kualitasnya produknya terhadap peminatan pembelian didapat koefisien regresinya 0,231 dan t-hitungnya besaran 3,754 dan signifikansinya 0,000. Terjadi terdapat kesimpulan jadi kualitasnya produknya terpengaruh positif terhadap peminatan pembelian sepeda motor Honda, hingga hipotesisnya membuktikan.

2. Berdasarkan hasil uji parsial (t-hitung) pengaruh citra merek terhadap minat beli diperoleh koefisien regresi 0,451 dan t-hitung sebesar 2,702 dengan signifikansi 0,008. Jadi dapat disimpulkan bahwa citra merek berpengaruh positif terhadap minat beli sepeda motor Honda, sehingga hipotesis kedua terbukti.

3. Berdasarkan hasil uji parsial (t-hitung) pengaruh harga terhadap minat beli diperoleh koefisien regresi 0,562 dan t-hitung sebesar 2,971 dengan signifikansi 0,004. Jadi dapat disimpulkan bahwa harga berpengaruh positif terhadap minat beli sepeda motor Honda di Universitas Kadiri Jurusan Manajemen, sehingga hipotesis ketiga terbukti.

4. Dari hasil pengujian diperoleh nilai $F$ hitung sebesar 41,922 dengan signifikansi sebesar 0,000. Oleh karena nilai signifikansi lebih kecil dari $0,05(0,000<0,05)$, maka dapat disimpulkan bahwa penelitian ini berhasil membuktikan hipotesis keempat yang menyatakan "Kualitas produk, citra merek, dan harga memiliki pengaruh terhadap minat beli sepeda motor Honda".

\section{Saran}

Berdasarkan penelitian diatas maka penulis menyarankan beberapa hal sebagai berikut :

1. Bagi Perusahaan Honda

Perusahaan harus lebih meningkatkan kualitas produknya sehingga akan tercipta sepeda motor Honda yang lebih variatif dan dapat menarik perhatian konsumen. Langkah-langkah demikian diharapkan dapat mendorong munculnya minat beli konsumen akan produk-produk Honda yang diluncurkan di pasaran.

2. Peneliti Selanjutnya 
Peneliti selanjutnya dapat mengembangkan penelitian ini dengan menggunakan metode lain dalam meneliti kualitas produk, citra merek, harga, dan minat beli, misalnya melalui wawancara mendalam terhadap responden, sehingga informasi yang diperoleh dapat lebih bervariasi daripada angket yang jawabannya telah tersedia.

\section{DAFTAR PUSTAKA}

A, N. F., \& Soliha, E. (2017). KUALITAS PRODUK , CITRA MEREK DAN PERSEPSI HARGA TERHADAP PROSES KEPUTUSAN PEMBELIAN KONSUMEN SEPEDA MOTOR MATIC “ HONDA ." Jurnal Manajemen Teori Dan Terapan, (1), 1-20.

Apriliana, V. (2017). Pengaruh Citra Merk Kualitas Produk, Persepsi Dan Harga Word Of Mouth Terhadap Keputusan Pembelian. Skripsi, (1-187).

DAUD, I., DEFRIANSYAH, D., \& WELYY. (2016). PENGARUH CITRA MEREK, HARGA DAN KUALITAS PRODUK TERHADAP KEPUTUSAN PEMBELIAN SMARTPHONE SAMSUNG (Studi Kasus Mahasiswa Universitas Sriwijaya Indralaya) Doni Defriansyah 1 , Islahuddin Daud 2 , \& Welly Nailis 3. JURNAH ILMIAH MANAJEMEN BISNIS DAN TERAPAN, 2(2), 89-102.

Himawan, A. H. (2016). PENGARUH KUALITAS PRODUK DAN CITRA MERK DAN PROMOSI TERHADAP MINAT BELI NOTE BOOK ACER. Skripsi, 1132.

KARTIKA, A. Y. (2017). PENGARUH ATRIBUT PRODUK DAN PERSEPSI HARGA TERHADAP MINAT BELI PONSEL APPLE. Skripsi, 1-130.

Pangastuti, R. L. (2018). The Influence of Experiential Marketing And Service Quality

For being Reasonability of Customers Loyality Forming (Case Study of Beauty

Saloon of London Beauty Center “ LBC”). Ekonika: Jurnal Ekonomi Universitas

Kadiri, 2(2), 198. https://doi.org/10.30737/ekonika.v2i2.43

MARTONO, \& SETYO, I. S. (2014). Moh. Martono R.A.P dan Sri Setyo Iriani; Analisis Pengaruh Kualitas ... JURNAL ILMU MANAJEMEN, 2(April), 1-13.

Martopo, A. S. (2015). Pengaruh kualitas produk, citra merek dan daya tarik iklan terhadap keputusan pembelian pada produk jamu tolak angin pt. sido muncul. Skripsi, 1-117.

Ruhamak, M. D., \& Rahayu, B. (2016). Pengaruh Word Of Mouth Terhadap Purchase Intention Melalui Brand Image Pada Lembaga Kursus Bahasa Inggris Dynamic

English Course Pare. Jurnal Ekonomi Universitas Kadiri, 1(2), 188-204.

PRABOWO, I. J. K. G. (2016). PENGARUH CITRA MERK, KUALITAS PRODUK, PERSEPSI HARGA TERHADAP MINAT BELI. Skripsi, 1-131.

Prawira, B., \& Yasa, N. N. K. (n.d.). PENGARUH KUALITAS PRODUK CITRA MERK DAN PERSEPSI HARHGA TERHADAP MINAT BELI. Jurnal Tepak Manajemen Bisnis, 3642-3658.

Purnomo, E. (2016). LOKASI TERHADAP MINAT BELI KONSUMEN DALAM MEMBELI BERAS LOKAL ( STUDI KASUS DESA RAMBAH UTAMA ). Ekonomi \& Bisnis, 1-28.

Romadhiani, G. S., \& Hadi, S. P. (2015). KEPUTUSAN PEMBELIAN HONDA BRIO PADA KONSUMEN HONDA SEMARANG CENTER sekaligus . Hal ini tentu 
merupakan prestasi bagi perusahaan dalam memasarkan produk unggulan dengan kontribusi terbesar pada tahun 2015 yaitu sebesar $27,4 \%$ penjualan produk Honda . Hon. Jurnal Administrasi Bisnis, 1-9.

Ruhamak, M. D., \& Rahayu, B. (2016). Pengaruh Word Of Mouth Terhadap Purchase Intention Melalui Brand Image Pada Lembaga Kursus Bahasa Inggris Dynamic English Course Pare. Jurnal Ekonomi Universitas Kadiri, 1(2), 188-204. https://doi.org/http://dx.doi.org/10.30737/ekonika.v1i2.14

SABAR, M., MENDROFA, JAYA, \& KRISTUMAN. (2016). Pengaruh Harga , Citra Merek dan Kualitas Produk terhadap Minat Beli Domain . id. Manajemen, Strategi Bisnis, Dan Kewirausahaan, 2(April), 0-17. https://doi.org/10.13140/RG.2.1.1686.0565

Saputri, E. H. (2017). PADA LOYALITAS KONSUMEN ( Studi Pada Konsumen Pengguna Tas Elizabeth di Semarang ) SKRIPSI ( Studi Pada Konsumen Pengguna Tas Elizabeth di Semarang ). Skripsi.

WARDANI, H. S. (2015). PENGARUH KUALITAS PRODUK HARGA TERHADAP MINAT BELI KONSUMEN MUSLIM PADA JAIZAH BOUTIQU TLOGASARI SEMARANG. Skripsi, 1-144.

Yustiawan, O., \& Prijati. (2016). Ody Yustiawan Prijati Sekolah Tinggi Ilmu Ekonomi Indonesia ( STIESIA ) Surabaya. JUrnal Ilmu Dan Riset Manajemen, 5, 1-20. 